\title{
Wide prevalence of hybridization in two sympatric grasshopper species may be shaped by their relative abundances
}

\author{
Katja Rohde*, Yvonne Hau, Jessica Weyer and Axel Hochkirch
}

\begin{abstract}
Background: Hybridization between species is of conservation concern as it might threaten the genetic integrity of species. Anthropogenic factors can alter hybridization dynamics by introducing new potentially hybridizing species or by diminishing barriers to hybridization. This may even affect sympatric species pairs through environmental change, which so far has received little attention. We studied hybridization prevalence and the underlying behavioral mechanisms in two sympatric grasshopper species, a rare specialist (Chorthippus montanus) and a common generalist (Chorthippus parallelus). We conducted a mate choice experiment with constant intraspecific density and varying heterospecific density, i.e. varying relative frequency of both species.

Results: Mate choice was frequency-dependent in both species with a higher risk of cross-mating with increasing heterospecific frequency, while conspecific mating increased linearly with increasing conspecific density. This illustrates that reproductive barriers could be altered by environmental change, if the relative frequency of species pairs is affected. Moreover, we performed a microsatellite analysis to detect hybridization in twelve syntopic populations (and four allotopic populations). Hybrids were detected in nearly all syntopic populations with hybridization rates reaching up to $8.9 \%$. Genetic diversity increased for both species when hybrids were included in the data set, but only in the common species a positive correlation between hybridization rate and genetic diversity was detected.

Conclusion: Our study illustrates that the relative frequency of the two species strongly determines the effectiveness of reproductive barriers and that even the more choosy species (Ch. montanus) may face a higher risk of hybridization if population size decreases and its relative frequency becomes low compared to its sister species. The asymmetric mate preferences of both species may lead to quasi-unidirectional gene flow caused by unidirectional backcrossing. This might explain why genetic diversity increased only in the common species, but not in the rare one. Altogether, the hybridization rate was much higher than expected for a widely sympatric species pair.
\end{abstract}

\section{Background}

The impact of hybridization and the underlying mechanisms have become fascinating fields of research for evolutionary biologists and conservation biologists [1-3]. The causes and consequences vary among species. While natural hybridization is recognized as a significant evolutionary process $[4,5]$, anthropogenic hybridization is often negatively valued by conservation biologists [1]. However, the potential outcomes of hybridization probably do not differ between natural and anthropogenic scenarios.

\footnotetext{
*Correspondence: rohdek@uni-trier.de

Department of Biogeography, Trier University, D-54286 Trier, Germany
}

Hybridization can trigger speciation and could lead to new adaptations in a changing environment [4, 6-8]. It can increase genetic diversity if hybrids are fertile, niches are available and both parental species have a high fitness [9]. Furthermore, hybridization could counteract negative effects of a small population size such as inbreeding depression $[3,10]$ and could thus protect a species against extinction [11]. However, hybridization can also trigger the collapse of populations (and species) by genetic displacement [12] and thus the negative effects of hybridization on rare species dominate the discussion in conservation biology $[1,13,14]$. 
The main natural scenarios, in which hybridization takes place, are secondary contact zones of species after postglacial range expansions [15-17]. Anthropogenic drivers of hybridization include habitat loss, breakdown of ecological barriers or introduction of non-native or domesticated species $[1,6,13,18-21]$. Most studies on natural hybridization focus on parapatric species in secondary contact zones, whereas hybridization between widely sympatric species received only little attention [2, 15, 22-24]. Even though there is a recent increase in studies on speciation with gene-flow (e.g. [25]), it is often assumed that sympatric species have evolved reproductive barriers that allow them to coexist $[2,26]$. However, sympatric species do not necessarily occur in syntopy, i.e. they might differ in habitat affiliation, and thus might show a micro-allopatric distribution with several local hybrid zones (mosaic hybrid zones). Allotopy can reduce the negative effects of hybridization, but also might evolve as a consequence of such negative effects [27]. Even natural hybrid zones are influenced by anthropogenic factors and may for example be moving as a response of local hybridization equilibria to global warming [28]. Similar changes might occur for species pairs with allotopic distribution patterns, e.g. if ecological barriers break down due to habitat deterioration or alteration [24, 29, 30]. It is thus of high interest to study the patterns of hybridization in species pairs which are widely sympatric but only locally syntopic.

We investigated the hybridization prevalence and the underlying behavioral mechanisms in two sympatric grasshopper species, a rare specialist (Chorthippus montanus, Charpentier, 1825) and a common generalist (Chorthippus parallelus, Zetterstedt, 1821), which occur sympatrically in large parts of Eurasia. While Ch. montanus is a habitat specialist occurring in permanently moist habitats, Ch. parallelus is a habitat generalist which occurs in a variety of grassland habitats [31]. Ch. parallelus is well known as a model species for hybridization studies, forming one of the best studied hybrid zones with an Iberian subspecies in the Pyrenees [17, 32]. Previous studies have even shown that Ch. parallelus and Ch. montanus hybridize under laboratory conditions and that hybrids are fertile at least to the F2-generation [2, 33, 34]. Juvenile mortality of Ch. montanus $\widehat{O}$ - Ch. parallelus $\odot$ hybrids is $34 \%$ higher than in the parental species, while in Ch. parallelus $\widehat{O}-$ Ch. montanus 9 hybrids it is even lower than in the parental species. Egg mortality is $10 \%$ lower in F1 hybrids and $16 \%$ lower in F2 hybrids than in the parental species [34]. Both species are closely related and morphologically very similar, but differ in ecology $[2,31,35]$. Their songs have a similar structure, but differ in speed (Ch. montanus sings slower) [2, 33, 35]. Due to their close relationship and similar songs, and based upon the occurrence of intermediate phenotypes, hybridization has been suggested to occur in syntopic populations [35]. Ch. montanus is threatened by drainage of wetlands, abandonment of meadows, habitat fragmentation and increasing length of droughts [36]. During the last decades it has disappeared from nearly all sites $<400 \mathrm{~m}$ asl in our study region, suggesting that it may be strongly affected by climate change. It is thus of high interest to explore, whether hybridization might act as an additional threat for Ch. montanus and if it may increase in declining populations.

Hochkirch and Lemke [2] demonstrated that females of Ch. montanus strongly prefer conspecific males as mates, whereas such a preference was not found for females of Ch. parallelus or males of both species. This may present at least a unidirectional pre-mating barrier which may reduce the hybridization probability between both species. However, it is well known that encounter rate is a major factor influencing mate choice and choosiness of females [37-39] and that previous exposure to heterospecifics may increase hybridization risk [40]. Thus, we assumed that the encounter probability of heterospecific males strongly influences female mate choice also in Ch. montanus and that high heterospecific frequencies (i.e. skewed abundances) may trigger interspecific matings also between Ch. montanus females and Ch. parallelus males. We further hypothesized that the ongoing decline of $C h$. montanus may increase heterospecific encounter probabilities and thus hybridization risk to increase with decreasing population size. In order to test this hypothesis, we first performed a mate choice experiment, in which we analyzed the role of heterospecific density on mate choice when conspecific density remains constant. We expected an increasing hybridization risk with increasing heterospecific frequency and a linear increase of conspecific matings with increasing conspecific frequency. As hybridization was only proven under laboratory conditions it also aimed to test for the prevalence and extent of hybridization in the field. Therefore, we performed a microsatellite analysis in twelve syntopic and four allotopic populations. In order to detect potential drivers of hybridization and to test the hypothesis that hybridization risk increases with decreasing population size, we analyzed the hybridization rates for correlations with effective population size. As there is a strong altitudinal pattern in the decline of Ch. montanus, we also tested for correlations of hybridization rate and altitude. Finally, we examined the impact of hybridization on the genetic diversity of both species [12] in order to assess the direction of gene flow and to test for differences between the habitat specialist and the generalist.

\section{Methods}

Study species

Chorthippus montanus is a univoltine, hygrophilous grasshopper species, which occurs in moist habitat types such as marshes, peat bogs and water meadows [41-43]. 
The species is listed as threatened on red lists of several European countries [36]. In the study area (Fig. 1), it has a highly fragmented distribution and is mainly found on isolated wet meadows at altitudes $>400 \mathrm{~m}$ asl. On most of these meadows Ch. parallelus occurs, too, but the latter species usually occupies drier areas surrounding the wet habitat of Ch. montanus. Nymphs of Ch. parallelus hatch earlier than those of Ch. montanus and become adult ca. one month earlier [2, 44]. Adults of both species co-occur at least over a period of two to three months. Both species are flightless, but occasionally macropterous individuals occur, which are believed to represent the main dispersal units [31, 43]. Hybrids of both species produce intermediate songs and are morphologically either intermediate or similar to Ch. parallelus [2, 34].

The collection of genetic samples and live specimen for this research was permitted by the "Struktur- and Genehmigungsdirektion Nord" Rhineland-Palatinate.

\section{Mate choice experiment}

Nymphs of Ch. parallelus were collected on 30 June, those of Ch. montanus on 06 August 2010 at three meadows: Prosterath $\left(49^{\circ} 44^{\prime} 6.59^{\prime \prime N} ; 06^{\circ} 54^{\prime} 12.87^{\prime \prime} \mathrm{E}\right)$, Damflos $\left(49^{\circ} 40^{\prime} 4.18^{\prime \prime} \mathrm{N}, 06^{\circ} 59^{\prime} 33.52^{\prime \prime} \mathrm{E}\right)$ and Hoxel (49 $46^{\prime}$ $\left.22.16^{\prime \prime} \mathrm{N} ; 07^{\circ} 06^{\prime} 9.44^{\prime \prime} \mathrm{E}\right)$. Nymphs were reared in plastic terraria $(30 \times 19.5 \times 20.5 \mathrm{~cm})$ covered with soil and planted with grass, kept in climate chambers (Kälte Kamrath) at $25{ }^{\circ} \mathrm{C}$ and $65 \%$ RF. They were watered each day. Aeration was ensured with a mesh lid. Each terrarium was illuminated by two UV- and VIS emitting fluorescent tubes (Osram Biolux ${ }^{\oplus}$ L36W/965). Nymphs were raised in single species groups. Adult individuals were sorted out daily by species (based upon their morphology) and sex to ensure virginity (grasshoppers become sexually mature 1-2 weeks after final moult) and to ensure that females had no previous experience with any potential mates. Mate choice experiments took place in similar terraria with moist soil

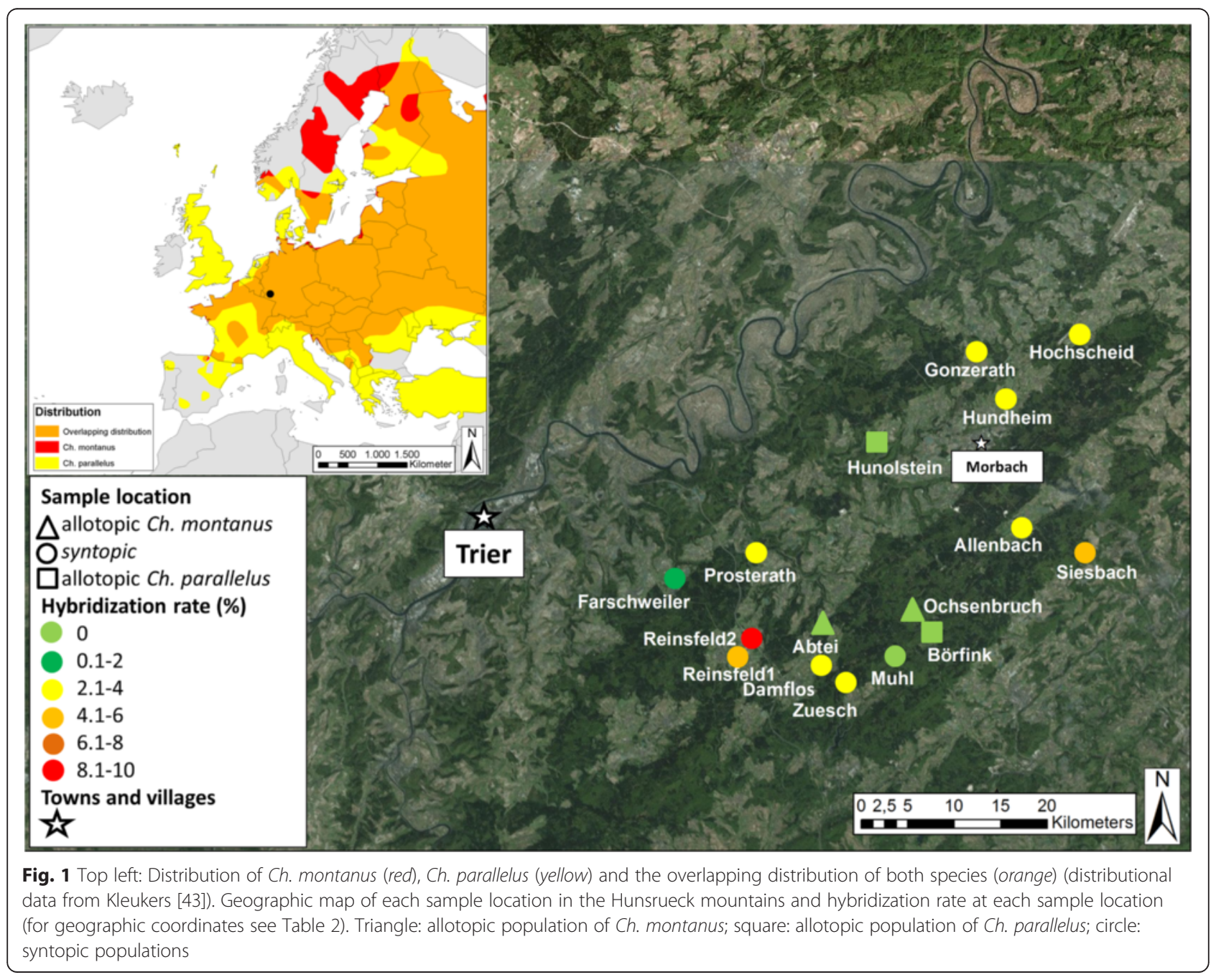


and grasses. We used a full factorial design with 40 replicates of four different factor levels (frequencies) for both species (Table 1). During each replicate we observed mate choice for $90 \mathrm{~min}$ at four different frequencies with one pair of the target species and either one, two, three or four heterospecific pairs (non-target pairs) (1:1, 1:2, 1:3, 1:4; Table 1). At each day, we conducted 3-9 replicates with randomly chosen factor levels. The terraria were inspected every 5 min (copulations last on average 37 min ranging from 15 to $90 \mathrm{~min}$ [45]) and all copulations were noted (time; type of copulation: target species conspecific, target female with heterospecific male, target male with heterospecific female, non-target species conspecific). Whenever a copulation occurred, the individuals involved were marked with a permanent non-toxic paint marker (Edding 780 ) and released in the terraria again to keep the density constant. After $90 \mathrm{~min}$, we sorted unmated individuals by species and sex. These individuals were never used as target species again, but males were used as non-target species in other replicates to increase the frequency of heterospecifics. Mated individuals were kept in separate terraria to breed them for later experiments.

\section{Statistical analysis of the mate choice experiment}

We analysed the effects of the explanatory variables (a) target species, (b) heterospecific density, (c) source locality and (d) time on the following response variables: (1) number of conspecific matings of the target species, (2) number of conspecific matings of the non-target species, (3) relative mating frequency of the non-target species (i.e. number of matings/pair), (4) number of interspecific matings with heterospecific males, (5) number of interspecific matings with heterospecific females, (6) time until first conspecific mating of both target and non-target species. For analysing the number of conspecific matings of the target species, we used generalized linear models (GLMs) with binomial data distribution. The number of conspecific matings of non-target species was also analysed with GLMs, but with Poisson distribution. We stepwise simplified all GLMs using the "step" function in R. As the

Table 1 Composition of the mate choice experiment

\begin{tabular}{|c|c|c|c|c|c|}
\hline \multirow{2}{*}{$\begin{array}{l}\text { Target } \\
\text { species }\end{array}$} & \multirow[t]{2}{*}{ Frequency } & \multicolumn{2}{|c|}{ Ch. montanus } & \multicolumn{2}{|c|}{ Ch. parallelus } \\
\hline & & $\bar{q}$ & $\hat{0}$ & $\bar{q}$ & 3 \\
\hline \multirow[t]{4}{*}{ Ch. montanus } & $1: 1$ & 1 & 1 & 1 & 1 \\
\hline & $1: 2$ & 1 & 1 & 2 & 2 \\
\hline & $1: 3$ & 1 & 1 & 3 & 3 \\
\hline & $1: 4$ & 1 & 1 & 4 & 4 \\
\hline \multirow[t]{4}{*}{ Ch. parallelus } & $1: 1$ & 1 & 1 & 1 & 1 \\
\hline & $1: 2$ & 2 & 2 & 1 & 1 \\
\hline & $1: 3$ & 3 & 3 & 1 & 1 \\
\hline & $1: 4$ & 4 & 4 & 1 & 1 \\
\hline
\end{tabular}

number of interspecific matings was rather low, we analysed these data either with $\chi^{2}$ tests or Fisher's exact tests (if the expected values were $<5$ ). The relative mating frequencies and the time until the first conspecific mating occurred were analysed with ANOVAs. The data were Box-Cox-transformed to infer the optimal exponent $(\lambda)$ to fit the data to the models assumptions. All statistical analyses were computed in R 3.1.1 [46].

\section{Genetic analyses \\ Data collection}

In 2009 and 2010 we sampled 1159 specimens (570 Ch. montanus, 561 Ch. parallelus and 28 intermediate morphotypes) from 16 localities in the Hunsrueck Mountains, Rhineland-Palatinate, Germany (Table 2, Fig. 1, for the exact sample size for each collected population see Table 3). We removed single hind legs of about 40 individuals per population and species. On 12 of these localities both species occurred syntopically, whereas Ochsenbruch represents a pure Ch. montanus population. In this case, we collected Ch. parallelus from a meadow in close vicinity. The localities Hunolstein and Abtei represent pure populations of Ch. parallelus and Ch. montanus, respectively, from which we only collected the respective species.

\section{Genotyping}

DNA was extracted from hind femur muscle tissue using the DNeasy Blood \& Tissue Kit (Qiagen). All individuals were genotyped at ten polymorphic microsatellite loci. Six microsatellite markers were designed for Ch. parallelus

Table 2 Geographic coordinates of each sample location in the Hunsrueck mountains (in decimal degrees; coordinate system WGS84), abbreviations of each location and altitude (in meters)

\begin{tabular}{lllll}
\hline Location & Abbreviation & X-coordinate & Y-coordinate & altitude \\
\hline Siesbach & S. & 7.226888 & 49.73729 & 456 \\
Hochscheid & H. & 7.217074 & 49.875070 & 507 \\
Zuesch & Z. & 7.010876 & 49.650941 & 509 \\
Allenbach & Ab. & 7.166868 & 49.754453 & 500 \\
Muhl & M. & 7.041020 & 49.671145 & 604 \\
Hundheim & Hd. & 7.152509 & 49.834350 & 473 \\
Abtei & A. & 6.966467 & 49.690865 & 500 \\
Reinsfeld1 & R1 & 6.883199 & 49.674076 & 480 \\
Reinsfeld2 & R2 & 6.899559 & 49.686529 & 525 \\
Farschweiler & F. & 6.827721 & 49.718864 & 392 \\
Damflos & D. & 6.984930 & 49.666523 & 540 \\
Prosterath & P. & 6.903598 & 49.735398 & 404 \\
Gonzerath & G. & 7.115982 & 49.863947 & 439 \\
Ochsenbruch & O. & 7.064372 & 49.694968 & 645 \\
Börfink & B. & 7.070153 & 49.685788 & 559 \\
Hunolstein & Hust. & 7.043359 & 49.802859 & 600 \\
\hline
\end{tabular}


Table 3 Number of hybrids detected in each population using STRUCTURE, NewHybrids and Adegenet (conservative estimate: hybrids detected by all three programs, relaxed estimate: hybrids detected by two programs), hybridization rate (in \%) and sample sizes for each population and species (pre-identified by morphology)

\begin{tabular}{|c|c|c|c|c|c|c|}
\hline \multirow[t]{2}{*}{ Pop } & \multirow{2}{*}{$\begin{array}{l}\text { Sample size } \\
\text { Ch. montanus }\end{array}$} & \multirow{2}{*}{$\begin{array}{l}\text { Sample size } \\
\text { Ch. parallelus }\end{array}$} & \multirow{2}{*}{$\begin{array}{l}\text { No. of hybrids } \\
\text { conservative }\end{array}$} & \multirow{2}{*}{$\begin{array}{l}\text { No. of hybrids } \\
\text { relaxed }\end{array}$} & \multirow{2}{*}{$\begin{array}{l}\text { Hybridization rate } \\
\text { conservative (\%) }\end{array}$} & \multirow{2}{*}{$\begin{array}{l}\text { Hybridization rate } \\
\text { relaxed (\%) }\end{array}$} \\
\hline & & & & & & \\
\hline Abtei & 45 & & 0 & 0 & 0 & 0 \\
\hline Allenbach & 40 & 39 & 2 & 5 & 2.5 & 6.17 \\
\hline Börfink & & 39 & 0 & 5 & 0 & 11.63 \\
\hline Damflos & 40 & 39 & 2 & 6 & 2.5 & 7.5 \\
\hline Farschweiler & 40 & 39 & 1 & 5 & 1.3 & 6.25 \\
\hline Gonzerath & 43 & 43 & 2 & 6 & 2.3 & 6.82 \\
\hline Hochscheid & 47 & 36 & 2 & 4 & 2.4 & 4.71 \\
\hline Hundheim & 41 & 39 & 3 & 7 & 2.4 & 8.54 \\
\hline Hunolstein & & 44 & 0 & 0 & 0 & 0 \\
\hline Muhl & 40 & 40 & 0 & 0 & 0 & 0 \\
\hline Ochsenbruch & 40 & & 0 & 3 & 0 & 6.98 \\
\hline Prosterath & 40 & 38 & 2 & 7 & 2.5 & 8.75 \\
\hline Reinsfeld1 & 36 & 42 & 5 & 9 & 6 & 10.84 \\
\hline Reinsfeld2 & 40 & 42 & 8 & 13 & 8.9 & 14.44 \\
\hline Siesbach & 38 & 38 & 5 & 6 & 5.8 & 6.98 \\
\hline Züsch & 40 & 39 & 2 & 3 & 2.5 & 3.7 \\
\hline total & 570 & 557 & 34 & 79 & 3.35 & 8.15 \\
\hline
\end{tabular}

(BF1, BD5, BH5, BD7, BF9, CD6; Molecular Ecology Resources Primer Development Consortium et al. 2009), four were developed for Ch. montanus prior to this study (Additional file 1). For PCR we used the Qiagen Multiplex Mastermix in multiplexed PCR protocols for a combination of two to four loci with the following annealing temperatures (BF1, BH5, CD6, CM37: $54{ }^{\circ} \mathrm{C}$; BD5, CM5: $48{ }^{\circ} \mathrm{C}$; CM33, CM19: $51{ }^{\circ} \mathrm{C}$; BD7, BF9: $\left.58{ }^{\circ} \mathrm{C}\right)$. PCR tubes were filled with $10 \mu \mathrm{l}$ reaction mixes $(5.5 \mu \mathrm{l}$ MultiplexMasterMix, $2 \mu \mathrm{l}$ water, $1.4 \mu \mathrm{l}$ genomic DNA (2-10 ng), 1.1 primer mix (1 $\mu \mathrm{M} /$ primer). The amplification was performed in a Multigene Gradient Thermal Cycler (Labnet) with the following PCR conditions: Initialization: $94{ }^{\circ} \mathrm{C} / 10 \mathrm{~min}$; Denaturation: $94{ }^{\circ} \mathrm{C} / 45 \mathrm{~s}$; Annealing: see primer/45 s; Extension: $72{ }^{\circ} \mathrm{C} / 45 \mathrm{~s}$; Final Extension: $72{ }^{\circ} \mathrm{C} / 30 \mathrm{~min}$; 37 cycles. Each forward primer was labeled with a fluorescent dye (FAM, HEX or TAMRA). Fragment lengths of PCR products were determined on a MEGABACE 1000 automated sequencer (GE Healthcare) and scored with Fragment Profiler 1.2 (Amersham Biosciences).

\section{Simulating and detecting hybrids}

In order to detect hybrids in the data set, we first simulated hybrids in HYBRIDLAB 1.1 [51]. This simulation was based upon a subset of 120 purebred individuals of each parental species, which were chosen from the complete data set after discarding potential hybrids discovered in preliminary analyses using three different programs. For the preliminary analyses we used STRUCTURE 2.3.4 and NewHybrids (both representing Bayesian approaches) and the $\mathrm{R}$ package adegenet 1.4-1 (which uses a discriminant analysis) [47-49]. The Structure analysis was run with the admixture model, a burn-in of $10^{4}$ simulations followed by $10^{5}$ Markov chain Monte Carlo (MCMC) simulations and a $\mathrm{K}$ of two with ten iterations. The posterior probability (q) belonging to one of the two clusters was used to identify hybrids without differentiation between different hybrid classes. The threshold qvalue for hybrids was chosen between 0.2 and 0.8 , as the simulation showed that a broader range led to an overestimate of hybridization caused by a higher number of mis-assigned pure-bred individuals, F1 and F2 hybrids (Fig. 2; Additional file 2). Hence, the threshold used here represents a conservative estimate of hybridization as has also been shown in other studies [12]. NewHybrids was developed to detect hybrids and distinguish different hybrid classes (i.e. F1, F2 and backcrosses [48]). The probabilities of each individual to belong to one of these hybrid classes were summed up and they were assigned to three categories based upon the maximum probability (i.e. either Ch. parallelus, Ch. montanus or hybrid). Posterior distributions were evaluated after $10^{5}$ iterations of the MCMC and a burn-in period of $10^{4}$ iterations. The third program adegenet 1.4-1 assigns genotypes to clusters 


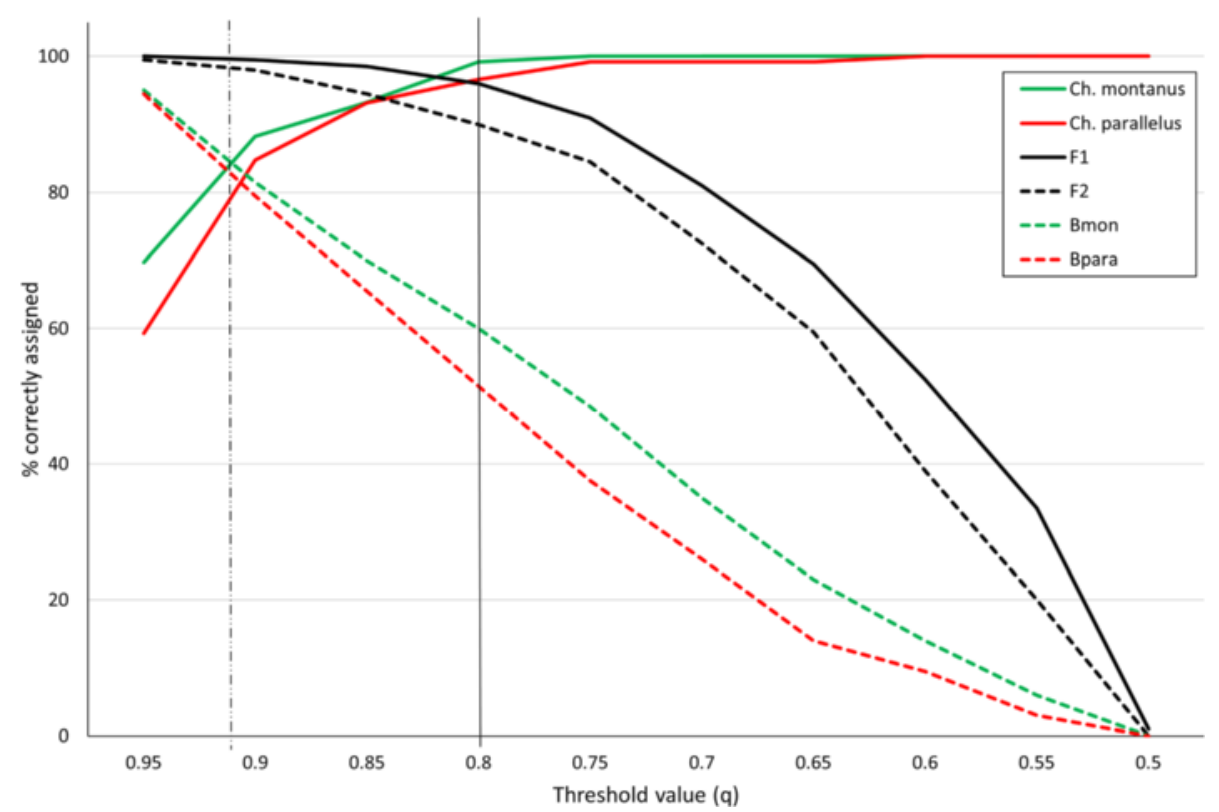

Fig. 2 Threshold value for the correct hybrid assignment in STRUCTURE. In total 800 hybrids ( 200 per hybrid class, F1, F2, Backcross with Ch. montanus = Bmon; Backcross with Ch. parallelus = Bpara) were simulated with HYBRIDLAB 1.1 [51] using purebred individuals from a previous analysis (119 Ch. montanus, 118 Ch. parallelus). Afterwards the STRUCTURE run was performed with $10^{5} \mathrm{MCMC}$ and a burn-in period of $10^{4}$ chains (with 10 iterations for $K=2$ )

based upon a discriminant analysis (DA), differentiating between hybrid classes. In this case, a prior assignment of all individuals to the classes is necessary. Therefore, individuals were assigned to a prior hybrid class, if this was suggested by both STRUCTURE and NewHybrids (only for the simulation study). The classification test assigned $90 \%$ of the genotypes correctly [49].

We simulated four classes of hybrids (F1, F2 and backcrosses with both species) with 200 individuals of each class in HYBRIDLAB 1.1 [51]. HYBRIDLAB allows a maximum of 120 individuals or individuals of each parental species to be included. Therefore, we first excluded all individuals identified as potential hybrids by at least two of the abovementioned programs. We then first included all individuals, which were collected from allotopic populations. The rest of parental individuals were randomly chosen from the dataset of purebred parental species. After simulating the hybrid classes, they were added to the dataset of parental individuals and the three abovementioned programs were used to determine the accuracy of hybrid detection by the different programs using the same settings.

The original dataset was then analyzed again using STRUCTURE, NewHybrids and adegenet (with the abovementioned conditions). Each individual was finally assigned to one of three classes: (1) Ch. parallelus, (2) Ch. montanus, (3) hybrid (including F1, F2 and backcrosses) using two different approaches: In the conservative assignment, we only assigned individuals as hybrids when they were detected by all three programs. In the relaxed assignment, we assigned individuals as hybrids when they were identified by at least two of the three programs. These two approaches were used to calculate the hybridization rate for each population (hybridization rate $=\mathrm{N}_{\mathrm{h}} / \mathrm{N} * 100 ; N=$ Total sample size of Ch. montanus and Ch. parallelus per population, $\mathrm{N}_{\mathrm{h}}=$ Number of detected hybrids). The conservative approach was used for any further analyses, whereas the relaxed approach was just calculated to obtain an upper estimate.

\section{Genetic diversity}

Expected and observed heterozygosities $\left(\mathrm{H}_{\mathrm{e}}\right.$ and $\left.\mathrm{H}_{\mathrm{o}}\right)$ were calculated using GenAlEx 6.5 [52]. The mean number of alleles per locus $(A)$ and allelic richness $\left(A_{R}\right)$ were analyzed in Fstat 2.9.3.2 [53]. These values were first calculated for each population of each species after excluding all hybrids detected by the conservative approach. In order to analyze the influence of hybrids on the genetic diversity of the populations, we performed a second analysis, in which we included the hybrids by assigning them to the parental population for which they had the highest assignment probability. In order to test for differences in genetic diversity in datasets with and without hybrids for each species, we only included populations where hybrids were detected and performed a paired $t$-test in R 3.0.2 [46]. Furthermore, allele frequencies, inbreeding coefficient $\left(\mathrm{F}_{\mathrm{IS}}\right)$ and tests of Hardy-Weinberg-Equilibrium (HWE) were calculated 
in GenAlEx 6.5 [52]. Fixation indices for genetic differentiation $\left(\mathrm{F}_{\mathrm{ST}}\right)$ between all populations of one species as well as between both species within syntopic and allotopic populations were also calculated in GenAlEx 6.5. Linkage disequilibria (based on 900 permutations and a nominal level of 1/100) between all pairs of loci were tested for each population of both species using Fstat 2.9.3.2 [53].

\section{Correlation analyses}

A linear regression analysis $(\mathrm{lm})$ was performed in $\mathrm{R}$ 3.0.2 to analyze the relationship between the genetic parameters $\left(\mathrm{A}, \mathrm{A}_{\mathrm{R}}, \mathrm{H}_{\mathrm{o}}, \mathrm{H}_{\mathrm{e}}\right)$ of the populations (including hybrids) and hybridization rate. As we expected a higher hybridization probability with decreasing population size (based upon the mate choice experiment), we also calculated a linear regression between effective population size and hybridization rate. Effective population size $\left(\mathrm{N}_{\mathrm{e}}\right)$ was calculated for each population and species using ONeSAMP1.2 [54]. Here we used the datasets without potential hybrids (based upon the conservative approach) to avoid an artificial overestimation of the population size caused by the inclusion of hybrids. Finally, we analyzed the correlation between hybridization rate and altitude of the twelve syntopic populations (Table 2), because Ch. montanus went extinct at localities $<400 \mathrm{~m}$ during the last decades.

\section{Results}

\section{Mate choice experiment}

The complete number of copulations was similar among species (Ch. montanus: 150, Ch. parallelus: 155). Relative mating frequency of non-target pairs remained more or less constant among treatments (mean: $0.28 \pm 0.02$ ) and was not significantly affected by density or species. Altogether, we observed 34 interspecific matings (26 between Ch. montanus males and Ch. parallelus females and eight between Ch. parallelus males and Ch. montanus females). The number of conspecific matings of the target species did not differ significantly between species. However, it decreased in both species significantly with increasing density of heterospecifics (GLM, $\mathrm{Rd}=196.4$, $\mathrm{df}=316, z=-4.02, p<0,001$; Fig. 3a).

The number of conspecific matings of the non-target species was also similar between species, but for both species the number of matings increased with increasing number of conspecifics (GLM, $\mathrm{Rd}=250.9, \mathrm{df}=318, z=$ 7.41, $p<0,001$; Fig. 3b). Target females of Ch. parallelus were more often involved in interspecific matings $(12 \mathrm{x})$ than those of Ch. montanus ( $3 \mathrm{x} ; \chi^{2}$ test, $\mathrm{df}=1, \chi^{2}=4.48$, $p=0.034$; Fig. 3c), whereas the opposite was true for males (14 x for Ch. montanus males, $3 \mathrm{x}$ for Ch. parallelus males; $\chi^{2}$ test, $\left.\mathrm{df}=1, \chi^{2}=6.21, p=0.013\right)$. Interspecific matings of Ch. montanus target females were not significantly affected by density (Fisher's Exact Test, $p=$ 0.059 ), but only occurred at a density of $1: 4$, whereas in Ch. parallelus females the number of interspecific matings increased significantly with increasing heterospecific density (Fisher's Exact Test, $p=0.045$; Fig. 3c). For males, no significant effects of heterospecific density on interspecific mating frequency were found (Fisher's Exact Test, Ch. montanus: $p=0.47$, Ch. parallelus: $p=0.99$ ). The time until a mating occurred varied between 28 and

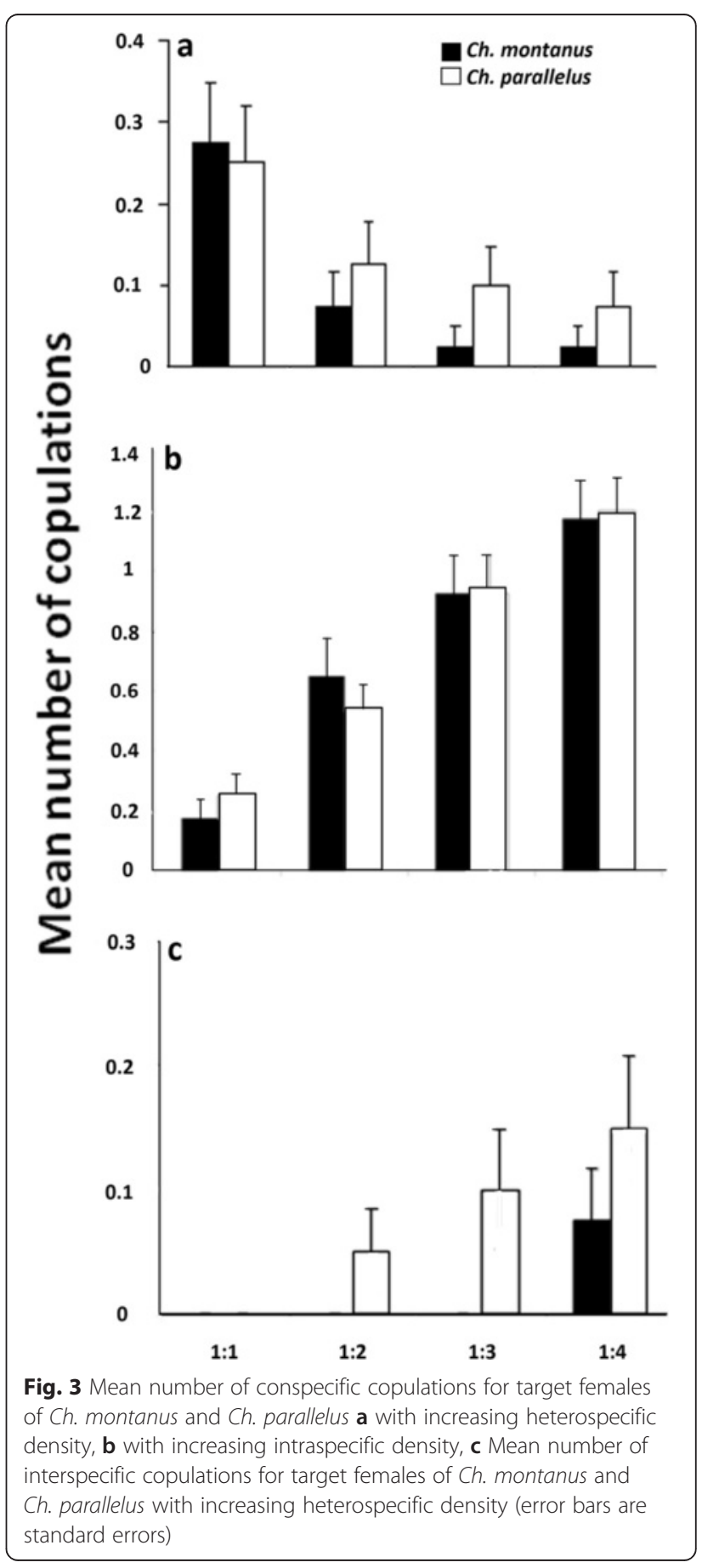


65 minutes and was not significantly influenced by either density or species (ANOVA, Ch. montanus: $\lambda=$ $0.64, \mathrm{~F}_{1,71}=0.67, p=0.42 ;$ Ch. parallelus: $\lambda=0.5, \mathrm{~F}_{1,69}$ $=0.84, p=0.36$ ).

\section{Hybridization rate}

After simulating a total of 800 hybrids (F1, F2, backcrosses with Ch. montanus and Ch. parallelus) in HYBRIDLAB, we tested the performance of the three programs by evaluating their assignment of the simulated hybrids (Additional file 2). The program NewHybrids had the best performance with an accuracy of $90 \%$, when hybrids were assigned to the respective hybrid class at an estimated posterior probability $>0.5$. Adegenet detected $88 \%$ of the simulated hybrids correctly and STRUCTURE detected $82 \%$ at a q value between 0.2 and 0.8 (Fig. 4a).

When we performed the same analysis with the original dataset (excluding simulated hybrids), we detected
34 hybrids using the conservative approach. With the relaxed approach we identified 79 hybrids, i.e. 46 hybrids were detected by only two programs, 23 of which were assigned as backcrosses with one of the parental species by NewHybrids and adegenet. In STRUCTURE, we assigned these individuals as purebred species at the chosen threshold of $q>0.8$ (Fig. 4b, Additional file 3).

The hybridization rate of all tested populations varied between 0 and $8.9 \%$ for the conservative approach and between 0 and $14.4 \%$ for the relaxed approach (Table 3 ). The highest hybridization rates were found in the populations Reinsfeld1 (conservative: 6.0; relaxed: 10.84) and Reinsfeld2 (conservative: 8.9 ; relaxed: 14.44). In the relaxed approach, eight hybrids were also detected in the allotopic populations Ochsenbruch and Börfink, suggesting that this approach provides an overestimate. These hybrids were assigned as backcrosses with Ch. montanus (3x) for Ochsenbruch and Ch. parallelus (5x) for

a

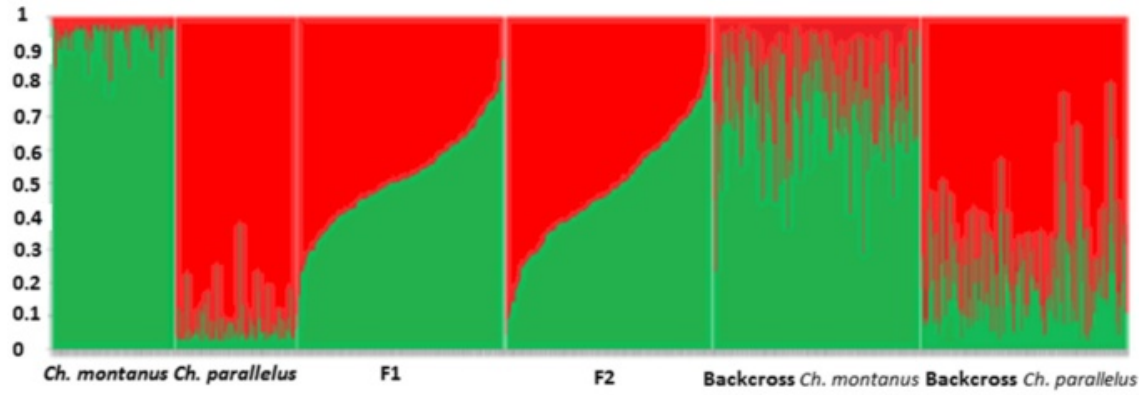

b
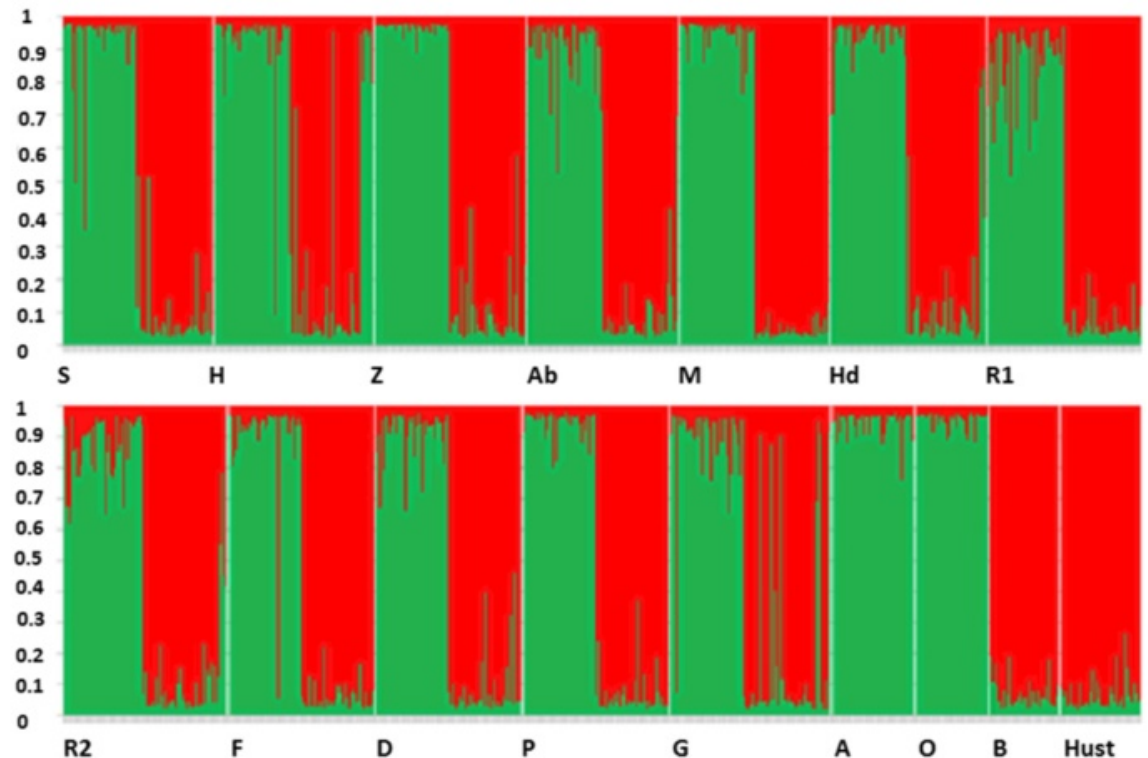

Fig. 4 Genetic clusters found by STRUCTURE for $\mathbf{a}$ the simulated hybrid-classes and $\mathbf{b}$ the 16 sampled populations. Each individual is represented by a single vertical line, divided into $K$ colours ( $K=2$; Ch. montanus: green; Ch. parallelus: red); the coloured segment shows the individual's estimated proportion of membership to that genetic cluster; abbreviations correspond to $\mathbf{a}$ the simulated hybrid-classes and to $\mathbf{b}$ the 16 sampled populations. The STRUCTURE run was performed with $10^{5} \mathrm{MCMC}$ and a burn-in period of $10^{4}$ chains (with 10 iterations for each K). Populations $\mathrm{O}$ and A. were allotopic populations of Ch. montanus, B and Hust. were allotopic populations of Ch. parallelus 
Börfink. No hybrids were detected in the other allotopic populations (Hunolstein and Abtei) in any analysis.

\section{Genetic variability and diversity}

The mean number of alleles was $11.44 \pm 0.44$ for $C h$. montanus (excluding hybrids of the conservative assignment). Including the hybrids increased the mean number of alleles significantly by $8.3 \%$ (paired $t$-test: $t=-3.9, \quad \mathrm{df}=10, P=0.003$; Table 4). Similarly, the number of alleles in Ch. parallelus populations increased from $15.6 \pm 0.63$ by $5.3 \%$ when hybrids were included (paired $t$-test: $t=-4.68, \mathrm{df}=10, \quad P=0.001$; Table 5). When including hybrids, expected heterozygosity $\left(\mathrm{H}_{\mathrm{e}}\right)$ declined significantly by $1.04 \%$ for $\mathrm{Ch}$. parallelus (paired $t$-test: $t=3.89, \mathrm{df}=10, P=0.003$ ), but increased (not significantly) by $1.2 \%$ for $C h$. montanus paired $t$-test: $t=-2.09, \quad \mathrm{df}=10, P=0.064$; Tables 4,5$)$. There was no significant difference in observed heterozygosities $\left(\mathrm{H}_{\mathrm{o}}\right)$ between the datasets with and without hybrids (Tables 4, 5).

For some loci species-specific alleles were evident, e.g. in locus CM33 alleles 298-313 were common in Ch. parallelus but rare in Ch. montanus, while alleles 316-328 were common in Ch. montanus and rare in Ch. parallelus (Additional file 4). We found no linkage disequilibria for any locus combination (Additional file 5). Many loci deviated significant from HWE (Additional file 6). $F_{\text {IS }}$ values were generally positive, independent of whether hybrids were included in the data set or not. Even though the number of significant deviations from HWE increased in Ch. montanus when including hybrids, FIS values showed no significant decrease (or increase). $\mathrm{F}_{\mathrm{ST}}$ values between species were significantly lower when hybrids were included than when excluding hybrids (paired $t$-test: $t=2.94, \mathrm{df}=13, P=0.012$; Additional file 7). FST values between populations within one species increased significantly when excluding hybrids (Ch. montanus: paired $t$-test: $t=4.04, \mathrm{df}=13, P=0.0014 ; C h$. parallelus: paired $t$-test: $t=3.84, \mathrm{df}=13, P=0.002$; Additional file 7).

\section{Correlation Analyses}

We found no significant correlation between hybridization rate and any genetic parameter for Ch. montanus or altitude. However, for Ch. parallelus we found a significant positive correlation between hybridization rate and the number of alleles $\left(\mathrm{R}^{2}=0.41, \mathrm{~F}_{1,12}=8.3, P=0.014\right.$; Fig. 5). The correlation of hybridization rate and $\mathrm{N}_{\mathrm{e}}$ was not significant, but for the populations of Ch. montanus there was a rather high coefficient of determination $\left(R^{2}=0.22\right.$, $\left.\mathrm{F}_{1,10}=2.8, P=0.126\right)$ with hybridization rate increasing with decreasing $\mathrm{N}_{\mathrm{e}}$.

\section{Discussion}

Despite the widespread assumption that hybridization between sympatric species is rare, our results show that even species with broadly overlapping ranges hybridize in nature. Although the two grasshopper species differ in their habitat requirements and phenology, niche overlap is strong enough to allow a considerable amount of heterospecific encounters in the field (twelve of the $14 \mathrm{Ch}$. montanus populations were in contact with Ch. parallelus). Nevertheless, hybridization rate

Table 4 Genetic parameters of each Ch. montanus population with hybrids (+) and excluding hybrids detected with the conservative approach (-); N: sample size; A: mean number of alleles; $\mathrm{H}_{0}$ and $\mathrm{H}_{e}$ observed and expected heterozygosities; Ne: mean effective population size estimate numbers in parentheses are standard errors

\begin{tabular}{llllllllll}
\hline Pop & $\mathrm{N}+$ & $\mathrm{N}-$ & $\mathrm{A}+$ & $\mathrm{A}-$ & $\mathrm{Ho}+$ & $\mathrm{Ho}-\mathrm{He}+$ & $\mathrm{He}-$ \\
\hline S. & 41 & 37 & $9.9(1.4)$ & $6.7(1.1)$ & $0.57(0.09)$ & $0.59(0.09)$ & $0.69(0.09)$ & $0.64(0.09)$ & 40.3 \\
H. & 47 & 46 & $13.2(1.5)$ & $12.9(1.5)$ & $0.66(0.06)$ & $0.67(0.06)$ & $0.81(0.03)$ & $0.81(0.03)$ & 667.7 \\
Z. & 41 & 40 & $12.0(1.7)$ & $11.0(1.6)$ & $0.69(0.07)$ & $0.70(0.07)$ & $0.80(0.04)$ & $0.80(0.04)$ & 142.7 \\
Ab. & 40 & 38 & $12.4(1.6)$ & $11.8(1.6)$ & $0.65(0.06)$ & $0.65(0.06)$ & $0.80(0.04)$ & $0.79(0.04)$ & 512.2 \\
M. & & 38 & & $12.2(1.8)$ & & $0.71(0.05)$ & & $0.80(0.03)$ & 389.4 \\
Hd. & 42 & 40 & $12.5(1.6)$ & $11.5(1.7)$ & $0.65(0.06)$ & $0.66(0.06)$ & $0.80(0.04)$ & $0.79(0.04)$ & 267.9 \\
A. & & 44 & & $10.7(1.6)$ & & $0.60(0.06)$ & & $0.78(0.03)$ & 122.3 \\
R1. & 39 & 35 & $11.5(1.6)$ & $10.7(1.5)$ & $0.67(0.06)$ & $0.67(0.06)$ & $0.79(0.03)$ & $0.78(0.03)$ & 128.4 \\
R2. & 46 & 38 & $11.9(1.7)$ & $11.1(1.6)$ & $0.57(0.07)$ & $0.59(0.08)$ & $0.75(0.06)$ & $0.75(0.05)$ & 170.9 \\
F. & 40 & 39 & $11.8(1.7)$ & $11.1(1.6)$ & $0.63(0.06)$ & $0.63(0.06)$ & $0.75(0.04)$ & $0.75(0.05)$ & 184.1 \\
D. & 39 & 37 & $13.9(2.0)$ & $13.3(2.0)$ & $0.63(0.06)$ & $0.63(0.07)$ & $0.79(0.04)$ & $0.79(0.04)$ & 656.5 \\
P. & 38 & 36 & $12.2(1.7)$ & $11.0(1.6)$ & $0.60(0.07)$ & $0.59(0.07)$ & $0.78(0.05)$ & $0.77(0.05)$ & 295.9 \\
G. & 44 & 42 & $14.7(1.9)$ & $14.5(1.8)$ & $0.68(0.06)$ & $0.69(0.07)$ & $0.80(0.04)$ & $0.80(0.04)$ & 671.01 \\
O. & & 37 & & $11.6(1.6)$ & & $0.57(0.07)$ & & $0.75(0.04)$ & 615.9 \\
Mean & 41 & 39 & $12.2(0.4)$ & $11.4(0.4)$ & $0.64(0.02)$ & $0.64(0.02)$ & $0.78(0.01)$ & $0.77(0.01)$ & \\
\hline
\end{tabular}


Table 5 Genetic parameters of each Ch. parallelus population with hybrids ( + ) and excluding hybrids detected with the conservative approach (-); N: sample size; A: mean number of alleles; $\mathrm{H}_{0}$ and $\mathrm{H}_{e}$ observed and expected heterozygosities; $\mathrm{N}_{e}$ : mean effective population size estimate; numbers in parentheses are standard errors

\begin{tabular}{llllllllll}
\hline Pop. & $\mathrm{N}+$ & $\mathrm{N}-$ & $\mathrm{A}+$ & $\mathrm{A}-$ & $\mathrm{Ho}+$ & $\mathrm{Ho}-$ & $\mathrm{He}+$ & $\mathrm{He}-$ \\
\hline S. & 39 & 34 & $16.7(2.4)$ & $15.0(2.2)$ & $0.58(0.06)$ & $0.59(0.06)$ & $0.80(0.04)$ & $0.81(0.04)$ & $4,097.7$ \\
H. & 32 & 31 & $14.3(1.9)$ & $14.3(1.9)$ & $0.45(0.07)$ & $0.45(0.07)$ & $0.76(0.06)$ & $0.76(0.06)$ & $14,598.3$ \\
Z. & 38 & 36 & $17.0(2.6)$ & $16.6(2.5)$ & $0.61(0.07)$ & $0.61(0.07)$ & $0.81(0.06)$ & $0.81(0.06)$ & $23,716.16$ \\
M. & & 36 & & $14.3(2.3)$ & & $0.59(0.05)$ & & $0.8(0.04)$ & $8,574.6$ \\
Hd. & 40 & 38 & $17.6(2.6)$ & $17.0(2.6)$ & $0.59(0.04)$ & $0.59(0.04)$ & $0.81(0.04)$ & $0.81(0.04)$ & $11,870.7$ \\
Ab. & 32 & 30 & $14.6(2.7)$ & $14.0(2.6)$ & $0.51(0.08)$ & $0.51(0.08)$ & $0.76(0.04)$ & $0.76(0.07)$ & $4,957.3$ \\
R1. & 46 & 41 & $18.8(2.4)$ & $17.3(2.5)$ & $0.68(0.06)$ & $0.68(0.07)$ & $0.77(0.06)$ & $0.77(0.06)$ & $8,819.9$ \\
R2. & 49 & 41 & $18.0(2.2)$ & $16.2(2.0)$ & $0.64(0.07)$ & $0.67(0.08)$ & $0.77(0.06)$ & $0.77(0.06)$ & $4,283.3$ \\
F. & 38 & 37 & $14.8(2.4)$ & $14.3(2.5)$ & $0.52(0.09)$ & $0.52(0.09)$ & $0.78(0.07)$ & $0.78(0.07)$ & $4,192.2$ \\
D. & 39 & 37 & $16.0(2.8)$ & $15.1(2.8)$ & $0.58(0.08)$ & $0.58(0.08)$ & $0.77(0.08)$ & $0.77(0.07)$ & $9,989.2$ \\
P. & 39 & 37 & $16.8(2.6)$ & $16.1(2.5)$ & $0.60(0.08)$ & $0.60(0.08)$ & $0.78(0.08)$ & $0.79(0.07)$ & $7,849.2$ \\
G. & 43 & 41 & $16.7(2.6)$ & $16.3(2.5)$ & $0.55(0.06)$ & $0.55(0.06)$ & $0.77(0.06)$ & $0.78(0.07)$ & $19,020.4$ \\
B. & & 37 & & $15.4(2.8)$ & & $0.59(0.08)$ & & $0.78(0.07)$ & $1,489.4$ \\
Hust & & 39 & & $16.5(2.4)$ & & $0.62(0.05)$ & & $0.82(0.04)$ & $10,285.4$ \\
Mean & 39 & 37 & $16.3(0.6)$ & $15.6(0.6)$ & $0.58(0.02)$ & $0.58(0.02)$ & $0.80(0.02)$ & $0.78(0.02)$ & \\
\hline
\end{tabular}

seems to be low enough to prevent a complete admixture of populations of both species. Furthermore, our lab experiment shows that hybridization risk increases with decreasing population size, i.e. increasing heterospecific encounter frequency (while increasing conspecific density did not affect the individual mating frequencies for both species). Ch. montanus is sensitive to droughts and habitat deterioration and has shown considerable population decline in the study area (Rohde unpublished observations), whereas Ch. parallelus has stable (or even increasing) populations. This suggests that small Ch. montanus populations might face an additional risk of being genetically displaced by Ch. parallelus.

\section{Evidence of hybridization}

Natural hybridization between Ch. montanus and Ch. parallelus was first proposed by Chládek [55], who found individuals with mixed morphological characters in Slovakia. However, these morphological intermediate individuals from the Slovakian Tatry Mts. have meanwhile been described as a new species, Chorthippus smardai [56]. Reynolds [35] also recognized morphologically intermediate individuals and suspected hybridization in the wild. Other studies have shown that these two species hybridize at least under laboratory conditions with very low fitness loss of the F1 and F2 generations [2, 34]. Our study provides the first genetic evidence that both species hybridize also in nature. In nearly all syntopic populations (except for Muhl) we identified hybrids. The hybridization rate reached a maximum of $8.9 \%$ (but may reach up to $14.44 \%$ when accepting the relaxed approach). The three programs varied in hybrid detection accuracy with NewHybrids performing best. Nevertheless, we recommend our approach of using all three programs as well as a prior simulation of hybrids to avoid an overestimation by a single program. With the relaxed approach we even detected hybrids in allotopic populations, which we believe to be unrealistic, even though one might argue that macropterous heterospecific individuals might occasionally immigrate. It also must be considered that STRUCTURE distinguishes neither hybrid generation nor backcrosses, which could lead to mis-assignments in some cases, leading to a more conservative estimate.

Ch. montanus and Ch. parallelus occur sympatrically in large parts of the Palearctic. It is thus surprising that both species regularly hybridize in nature. However, the contact between both species might be rather recent (in evolutionary terms), because $C h$. parallelus recolonized large parts of its range during the postglacial period from Mediterranean refugia [57, 58]. The colonization history of Ch. montanus has not been reconstructed yet, but it does not occur in the Mediterranean and is generally found further north $[43,59]$. This suggests that it might have colonized the temperate zone earlier or even survived here during the last glacial maximum. Hence, one may speculate that $C h$. montanus reached its large geographic range earlier. With ongoing warming it might have become more and more restricted to higher altitudes and came in contact with $C h$. parallelus that still expands its range [60]. 


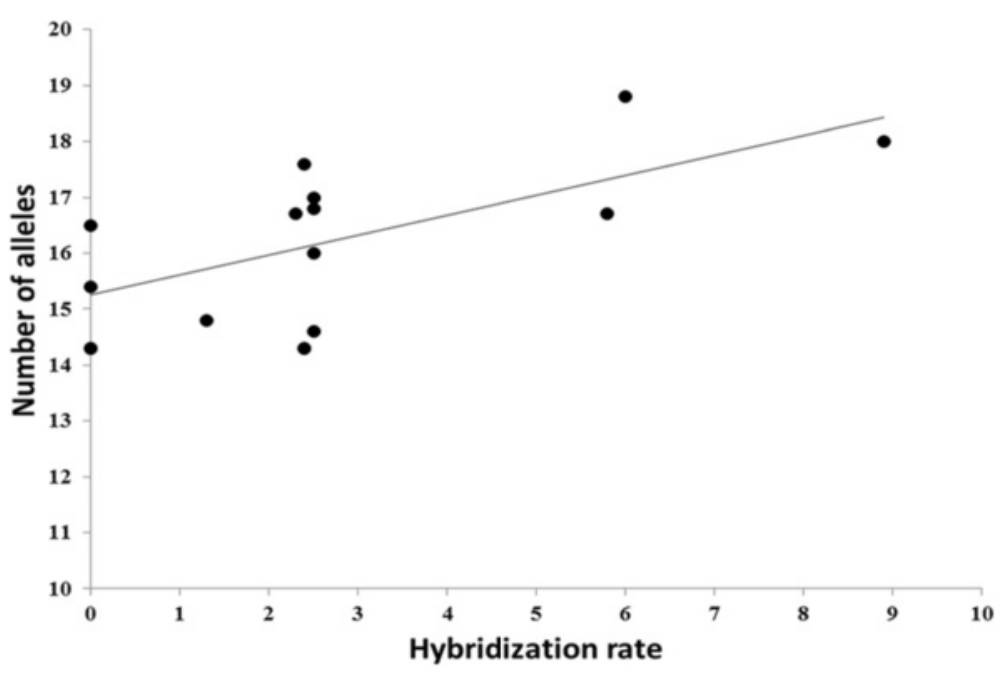

Fig. 5 Correlation between hybridization rate (\%) and number of alleles (A) of Ch. parallelus populations $\left(R^{2}=0.41\right)$

As we found hybrids in nearly all populations and hybrids are known to have nearly no fitness loss [34], the question arises why the species do not mix up completely and build hybrid swarms [12]. Either the hybridization rate is still low enough to avoid complete admixture, or hybrid fitness is much lower in the field than in the lab, possibly due to mismatches of traits acting as premating barriers. Three premating barriers are usually considered important for this species pair: (1) distinct songs of both species [61], (2) differing habitat preferences, resulting from specific drought sensitivity of the eggs [34, 41], (3) differences in the phenology with $C h$. parallelus becoming adult ca. one month earlier than Ch. montanus [34]. It has recently been shown that the latter two aspects substantially reduce hybridization risk of both species in the field (Rohde unpublished observations). Hybrids have intermediate habitat preferences and phenologies. Thus, it is unlikely that these aspects will act as efficient barriers to backcrossing of hybrids. The intermediate song of hybrids [2] might indeed act as an efficient barrier to backcrossing hybrids, but the song differences of the parental species are much stronger and should prevent hybridization in the first place. Hence, it remains unresolved, if the lack of complete admixture is caused by such barriers or by the low hybridization rate. It is also possible that backcrosses mainly occur in one direction (with $\mathrm{Ch}$. parallelus females), so that quasi-unidirectional gene flow occurs.

\section{Population size and hybridization risk}

Our results confirm that females of Ch. montanus have a much stronger preference for conspecific males than females of Ch. parallelus [2]. Such an asymmetric reproductive isolation seems to be common and is attributed to the ecological and reproductive differences among sexes and species [27, 62, 63]. Differences in courtship songs of both species or even dissimilarities in pheromones (cuticular hydrocarbons) between both species could provide the underlying mechanism in the discrimination of Ch. montanus [64, 65]. However, the role of pheromones in mate choice of these species has not been studied so far. This unidirectional barrier combined with the differences in habitat requirements and phenology may protect natural populations of Ch. montanus from rapid admixture with Ch. parallelus. This would be in line with the assumption that multiple barriers cause restriction of gene flow between closely related species [66]. We assume that the asymmetry in female choosiness has evolved as a consequence of the different encounter probabilities caused by their differing ecology and distribution. While most Ch. montanus populations occur in syntopy with $\mathrm{Ch}$. parallelus, the latter species has a very wide distribution and occurs only rarely syntopically with Ch. montanus. Therefore, selection pressure on reproductive barriers affects a higher proportion of Ch. montanus females, but only a very small proportion of Ch. parallelus females [62, 67]. However, it is also possible that the lower choosiness is caused by the age of females. As Ch. parallelus becomes adult earlier, they might have a reduced choosiness (i.e. higher receptivity) than those of Ch. montanus, which are still younger.

The records of hybrids from natural populations show that hybridization is not an artifact produced by laboratory conditions. It confirms that interspecific mating occurs regularly in the wild despite the existence of ecological, phenological and ethological barriers. Mate choice strongly depends on the encounter rate of potential mates and the costs and benefits of mate choice [37, 39]. Low encounter rates with conspecific mates increase the costs of mate searching and reduce choosiness [37, 39]. Our 
mate choice experiment demonstrates a decreasing frequency of conspecific matings and an increasing number of cross-matings with increasing heterospecific density for females of both species, but females of Ch. montanus only chose heterospecific males at the highest density of heterospecifics (1:4). This suggests that even the bioacoustic differences of both species are not sufficient to ensure a "correct" mate choice. If the direct contact of individuals is more important for mate finding than the song, the encounter probabilities might determine hybridization risk [27]. Songs may only be important at low densities to find corresponding mates $[44,68]$.

The results of our lab experiment suggest that demography might be a major driver of hybridization in wild syntopic populations. We suppose that in large populations of Ch. montanus hybridization is rare and restricted to the periphery of the habitat, which might lead to the formation of a mosaic hybrid zone, but not to genetic displacement [34]. If a Ch. montanus population decreases in size and abundances become more and more skewed towards Ch. parallelus, the reproductive barrier might weaken as has been shown for other rare species [39, 62, 69, 70]. Hence, a population decline caused by land use change (abandonment), drainage or climate change [6,36] might lead to a vortex effect, increasing the strength of other threats such as hybridization. In fact, we monitored the population dynamics of the R1 and R2 populations from 2010 to 2014 (Rohde unpublished observations) and found that Ch. montanus declined by $90.3 \%$ on R 1 and by $49.6 \%$ on R2 during this period. We assume that the decline was mainly driven by weather conditions (there were severe droughts in spring and autumn 2011, which might have caused the severe population decline of R1 by $87 \%$ until 2012) or ongoing accumulation of grass debris at the sites due to abandonment. However, this population decline might increase the risk of future hybridization or even might be increasingly caused by hybridization itself.

\section{Genetic diversity and hybridization}

It is well known and consistent that hybridization increases genetic diversity within a population [12]. Population augmentation is therefore sometimes used in conservation management to avoid inbreeding depression at low population size [71]. As long as Ch. montanus populations remain large and stable, a leaky reproductive isolation could increase genetic variability [3, 10, 72]. However, hybridization can also lead to a near-complete genetic displacement of a species. Hedrick [73] compared introgression of red wolf populations from coyote populations with Wright's continent-island model [74], i.e. with unidirectional gene flow. This is probably an oversimplification as gene flow would necessarily affect both populations and thus would follow Wright's general island model, i.e. gene flow in both directions. This means that the larger gene pool of Ch. parallelus will displace the gene pool of Ch. montanus until an equilibrium is reached. A new, completely admixed population will thus conserve some $C h$. montanus alleles at a very low frequency (reinforced by heterosis; [75]). This is similar to Neanderthal alleles being still present in the human gene pool [76], but the genetic integrity of the Ch. montanus population would be lost [70]. By contrast, the genetic diversity of large populations of $C h$. parallelus increases with occasional hybridization. It remains unknown, whether this may represent an advantage (higher adaptability) or a risk (genetic incompatibilities) in the long term.

\section{Conclusions}

Our results support the hypothesis that hybridization between the sympatric sister species Ch. montanus and Ch. parallelus also occurs in the wild. We assume that naturally hybridization mainly takes place in ecotones between wetlands and drier habitat types, where both species come into contact. As cross-mating probability increased in the lab with decreasing relative frequency of conspecific mates, we conclude that the encounter rate is a major driver of hybridization. Population decline caused by stochastic and environmental fluctuation will thus increase the probability of hybridization as an additional threat. Habitat restoration and wetland management are therefore important tools to save this species from such vortex situations.

\section{Availability of Supporting Data}

The microsatellite data of this paper are deposited at Dryad data repository (doi:10.5061/dryad.1dd0m).

\section{Additional files}

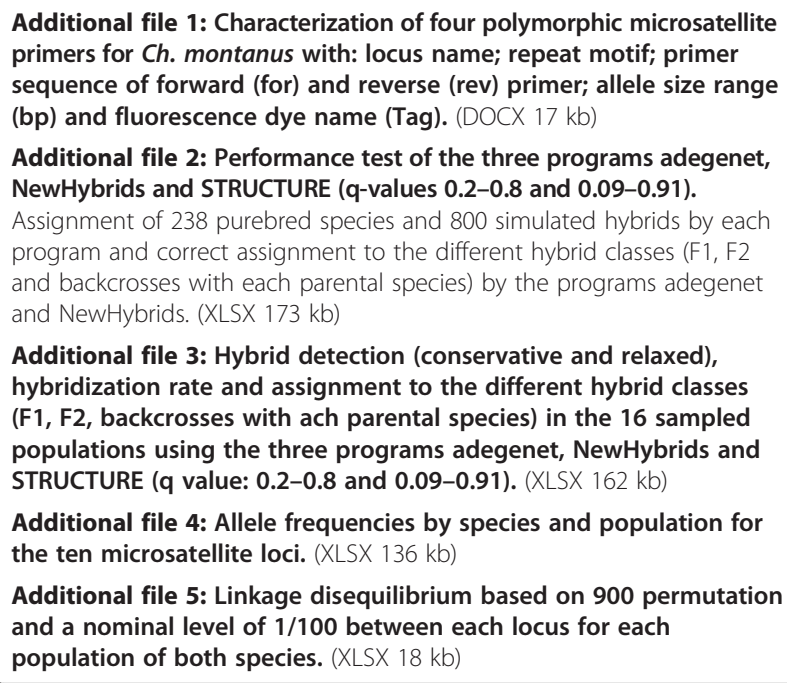
primers for Ch. montanus with: locus name; repeat motif; primer sequence of forward (for) and reverse (rev) primer; allele size range (bp) and fluorescence dye name (Tag). (DOCX $17 \mathrm{~kb}$ )

Additional file 2: Performance test of the three programs adegenet, NewHybrids and STRUCTURE (q-values $0.2-0.8$ and $0.09-0.91$ ). Assignment of 238 purebred species and 800 simulated hybrids by each program and correct assignment to the different hybrid classes (F1, F2 and backcrosses with each parental species) by the programs adegenet and NewHybrids. (XLSX 173 kb)

Additional file 3: Hybrid detection (conservative and relaxed), hybridization rate and assignment to the different hybrid classes (F1, F2, backcrosses with ach parental species) in the 16 sampled populations using the three programs adegenet, NewHybrids and STRUCTURE (q value: $0.2-0.8$ and 0.09-0.91). (XLSX $162 \mathrm{~kb}$ )

Additional file 4: Allele frequencies by species and population for the ten microsatellite loci. (XLSX $136 \mathrm{~kb}$ )

Additional file 5: Linkage disequilibrium based on 900 permutation and a nominal level of $1 / 100$ between each locus for each population of both species. (XLSX $18 \mathrm{~kb}$ ) 
Additional file 6: Deviations from Hardy-Weinberg-Equilibrium and inbreeding coefficient for both species and each population and locus. (XLSX $50 \mathrm{~kb}$ )

Additional file 7: Fixation indices for genetic differentiation $\left(F_{S T}\right)$ between the populations within one species and between the species in syntopic and allotopic populations. (XLSX $19 \mathrm{~kb})$

\section{Competing interests}

The authors declare that they have no competing interests.

\section{Authors' contributions}

Y.H. performed and analyzed the mate choice experiment. J.W. and A.H. collected samples for the genetic analysis. K.R., J.W. and Y.H. genotyped the collected samples. K.R. performed the genetic analyses. K.R. and A.H. performed the statistical analyses and discussed the interpretation of the data. K.R. wrote the manuscript with input by A.H. All authors read and approved the final version of this manuscript

\section{Acknowledgements}

We acknowledge the "Struktur- and Genehmigungsdirektion Nord" for permitting the collection of samples and access to nature reserves. We also acknowledge Jasmin Weinberger and Marielle Mayer for sampling as well as Elena Kaut and Bernd Schneider for laboratory assistance. The study was funded by the German Research Foundation (DFG, GRK 1319) in the interdisciplinary graduate school 'Cooperation of Science and Jurisprudence in Improving Development and Use of Standards for Environmental Protection - Strategies for Risk Assessment and Management' and by the "Forschungsinitiative Rheinland-Pfalz".

\section{Received: 26 May 2015 Accepted: 19 August 2015}

\section{Published online: 16 September 2015}

\section{References}

1. Rhymer JM, Simberloff D. Extinction by hybridization and introgression. Annu Rev Ecol Syst. 1996;27:83-109.

2. Hochkirch A, Lemke I. Asymmetric mate choice, hybridization, and hybrid fitness in two sympatric grasshopper species. Behav Ecol Sociobiol. 2011;65:1637-45.

3. Abbott R, Albach D, Ansell S, Arntzen JW, Baird SJE, Bierne N, et al. Hybridization and speciation. J Evol Biol. 2013;26:229-46.

4. Seehausen O. Hybridization and adaptive radiation. Trends Ecol Evol. 2004;19:198-207.

5. Genovart M. Natural hybridization and conservation. Biodivers Conserv 2009;18:1435-9.

6. Chunco AJ. Hybridization in a warmer world. Ecology and Evolution. 2014;4:2019-31.

7. Thornton DH, Murray DL. Influence of hybridization on niche shifts in expanding coyote populations. Divers Distrib. 2014;20:1355-64.

8. Salmon A, Ainouche ML, Wendel JF. Genetic and epigenetic consequences of recent hybridization and polyploidy in Spartina (Poaceae). Mol Ecol. 2005; 14:1163-75.

9. Mallet J. Hybridization as an invasion of the genome. Trends Ecol Evol. 2005;20:229-37.

10. Arnold ML, Sapir Y, Martin NH. Genetic exchange and the origin of adaptations: prokaryotes to primates. Philos Trans R Soc B. 2008;363:2813-20.

11. Baskett ML, Gomulkiewicz R. Introgressive hybridization as a mechanism for species rescue. Theor Ecol. 2011:4:223-39.

12. Schulte $U$, Veith $M$, Hochkirch $A$. Rapid genetic assimilation of native wall lizard populations (Podarcis muralis) through extensive hybridization with introduced lineages. Mol Ecol. 2012;21:4313-26.

13. Seehausen O, Takimoto G, Roy D, Jokela J. Speciation reversal and biodiversity dynamics with hybridization in changing environments. $\mathrm{Mol}$ Ecol. 2008;17:30-44.

14. Wolf DE, Takebayashi N, Rieseberg LH. Predicting the risk of extinction through hybridization. Conserv Biol. 2001;15:1039-53.

15. Barton NH, Hewitt GM. Adaptation, speciation and hybrid zones. Nature. 1989;341:497-503.

16. Hewitt GM. After the ice: parallelus meets erythropus in the Pyrenees. New York: Oxford University Press; 1993.
17. Butlin RK, Hewitt GM. A hybrid zone between Chorthippus parallelus parallelus and Chorthippus parallelus erythropus (Orthoptera: Acrididae): behavioural characters. Biol J Linn Soc. 1985;26:287-99.

18. Crispo E, Moore J-S, Lee-Yaw JA, Gray SM, Haller BC. Broken barriers: Human-induced changes to gene flow and introgression in animals. BioEssays. 2011;33:508-18.

19. Allendorf FW, Lundquist LL. Introduction: population biology, evolution, and control of invasive species. Conserv Biol. 2003;17:24-30.

20. Randi E. Detecting hybridization between wild species and their domesticated relatives. Mol Ecol. 2008;17:285-93.

21. Huxel GR. Rapid displacement of native species by invasive species: effects of hybridization. Biol Conserv. 1999;89:143-52.

22. Bettles CM, Docker MF, Dufour B, Heath DD. Hybridization dynamics between sympatric species of trout: loss of reproductive isolation. J Evol Biol. 2005;18:1220-33.

23. Buggs RJA. Empirical study of hybrid zone movement. Heredity. 2007:99:301-12

24. Hasselman DJ, Argo EE, McBride MC, Bentzen P, Schultz TF, Perez-Umphrey $A A$, et al. Human disturbance causes the formation of a hybrid swarm between two naturally sympatric fish species. Mol Ecol. 2014;23:1137-52

25. Feder JL, Egan SP, Nosil P. The genomics of speciation-with-gene-flow. Trends Genet. 2012;28:342-50.

26. Rundle HD, Schluter D. Reinforcement of stickleback mate preferences: sympatry breeds contempt. Evolution. 1998;52:200-8.

27. Gröning J, Hochkirch A. Reproductive interference between animal species. Q Rev Biol. 2008:83:257-82.

28. Engler JO, Rödder D, Elle O, Hochkirch A, Secondi J. Species distribution models contribute to determine the effect of climate and interspecific interactions in moving hybrid zones. J Evol Biol. 2013;26:2487-96.

29. Taylor EB, Boughman JW, Groenenboom M, Sniatynski M, Schluter D, Gow $J$. Speciation in reverse: morphological and genetic evidence of the collapse of a three-spined stickleback (Gasterosteus aculeatus) species pair. Mol Ecol. 2006;15:343-55

30. Seehausen O. Conservation: losing biodiversity by reverse speciation Curr Biol. 2006;16:R334-7.

31. Detzel P. Die Heuschrecken Baden-Württembergs. Stuttgart, Germany: Verlag Eugen Ulmer; 1998.

32. Butlin RK. What do hybrid zones in general, and the Chorthippus parallelus zone in particular, tell us about speciation. In: Howard DJ, Berlocher SH, editors. Endless forms: species and speciation Oxford Univ Press, New York. New York: Oxford Univ Press; 1998. p. 367-78.

33. Bauer $M$, von Helversen $O$. Separate localization of sound recognizing and sound producing neural mechanisms in a grasshopper. J Comp Physiol A. 1987;161:95-101.

34. Köhler G. Experimentelle Hybridisierung von Chorthippus parallelus (Zetterstedt, $\times$ Ch. montanus (Charpentier, 1825): Morphometrische und ökologische Parameter. Articulata 2013. 1821;28(1/2):13-40.

35. Reynolds WJ. A re-examination of the characters separating Chorthippus montanus and C. parallelus (Orthoptera:. Acrididae). J Nat Hist. 1980;14 (2):283-303.

36. Weyer J, Weinberger J, Hochkirch A. Mobility and microhabitat utilization in a flightless wetland grasshopper, Chorthippus montanus (Charpentier, 1825). J Insect Conserv. 2012;16:379-90.

37. Milinski M, Bakker TCM. Costs influence sequential mate choice in sticklebacks, Gasterosteus aculeatus. Proc R Soc Lond Ser B Biol Sci. 1992:250:229-33.

38. Gröning J, Lücke N, Finger A, Hochkirch A. Reproductive interference in two ground-hopper species: testing hypotheses of coexistence in the field. Oikos. 2007;116:1449-60.

39. Willis PM, Ryan MJ, Rosenthal GG. Encounter rates with conspecific males influence female mate choice in a naturally hybridizing fish. Behav Ecol. 2011;22:1234-40

40. Izzo AS, Gray DA. Heterospecific courtship and sequential mate choice in sister species of field crickets. Anim Behav. 2011;81:259-64.

41. Ingrisch S. Zum Einfluss der Feuchte auf die Schlupfrate und Entwicklungsdauer der Eier mitteleuropäischer Feldheuschrecken (Orthoptera, Acrididae). Deutsche Entomologische Zeitschrift. 1983;30:1-15.

42. Froehlich C. Analyse der Habitatpräferenzen von Heuschreckenarten (Orthoptera: Saltatoria) in einem Mittelgebirgsraum unter Berücksichtigung regionaler Differenzierungen. DGfO- Articulata. 1994;4:1-176. 
43. Kleukers R, Van Nieukerken EJ, Odé B, Willemse LPM, Van Wingerden W. De sprinkhanen en krekels van Nederland (Orthoptera). Leiden, Nederland: KNNV Uitgeverij \& EIS; 1997.

44. Ingrisch S, Köhler G. Heuschrecken Mitteleuropas. Magdeburg, Germany: Westarp Wissenschaften; 1998.

45. Reinhardt K. Determinants of ejaculate size in a grasshopper (Chorthippus parallelus). Behav Ecol Sociobiol. 2001;50:503-10.

46. R Development Core Team, editor. A language and environment for statistical computing. Vienna: R Foundation for Statistical Computing; 2014

47. Pritchard JK, Stephens M, Donnelly P. Inference of population structure using multilocus genotype data. Genetics. 2000;155:945-59.

48. Anderson EC, Thompson EA. A model-based method for identifying species hybrids using multilocus genetic data. Genetics. 2002;160:1217-29.

49. Jombart $\mathrm{T}$. adegenet: a $\mathrm{R}$ package for the multivariate analysis of genetic markers. Bioinformatics. 2008;24:1403-5.

50. Abercrombie, Laura G., et al. "Permanent genetic resources added to molecular ecology resources database 1 January 2009-30 April 2009." Molecular Ecology Resources 9.5 (2009): 1375-1379.

51. Nielsen EE, Bach LA, Kotlicki P. HYBRIDLAB (version 1.0): a program for generating simulated hybrids from population samples. Mol Ecol Notes. 2006:6:971-3.

52. Peakall R, Smouse PE. GenAlEx 6.5: genetic analysis in Excel. Population genetic software for teaching and research - an update. Bioinformatics. 2012;28:2537-9.

53. Goudet J. FSTAT, a program to estimate and test gene diversities and fixation indices (Version 2.9. 3). 2001.

54. Tallmon DA, Koyuk A, Luikart G, Beaumont MA. COMPUTER PROGRAMS: onesamp: a program to estimate effective population size using approximate Bayesian computation. Mol Ecol Resour. 2008;8:299-301.

55. Chládek F. Orthopterologische Notizen aus der Slowakai. Articulata. 1977;1(5):25.

56. Chládek F. Chorthippus smardai - eine neue Art aus der Nordslowakei (Orthoptera s.l., Caelifera, Acrididae). TETRIX 2. 2014. (10): 37-40.

57. Korkmaz EM, Lunt DH, Çıplak B, Değerli N, Başıbüyük HH. The contribution of Anatolia to European phylogeography: the centre of origin of the meadow grasshopper, Chorthippus parallelus. J Biogeogr. 2014;41(9):1793-805.

58. Cooper SJB, Ibrahim KM, Hewitt GM. Postglacial expansion and genome subdivision in the European grasshopper Chorthippus parallelus. Mol Ecol. 1995:4:49-60.

59. Karjalainen S. Suomen heinäsirkat ja hepokatit. Helsinki, Finland: Tammi Publishers; 2009

60. Hochkirch A, Klugbist H. Die Heuschrecken des Landes Bremen-ihre Verbreitung, Habitate und ihr Schutz (Orthoptera: Saltatoria). Abh Naturw Ver Bremen. 1998;44:3-73.

61. Faber A. Chorthippus longicornis Latr.(parallelus Zett.) und Chorthippus montanus Charp.(bisher nach Finot als" Iongicornis Latr." bezeichnet. Akad. Verlag-Ges. 1929.

62. Wirtz P. Mother species-father species: unidirectional hybridization in animals with female choice. Anim Behav. 1999;58:1-12.

63. Veen T, Faulks J, Rodríguez-Muñoz R, Tregenza T. Premating reproductive barriers between hybridising cricket species differing in their degree of polyandry. PLoS One. 2011;6:e19531.

64. Neems RM, Butlin RK. Divergence in cuticular hydrocarbons between parapatric subspecies of the meadow grasshopper, Chorthippus parallelus (Orthoptera, Acrididae). Biol J Linn Soc. 1995;54:139-49.

65. Howard RW, Blomquist GJ. Chemical ecology and biochemistry of insect hydrocarbons. Annu Rev Entomol. 1982;27:149-72.

66. Coyne JA, Orr HA. Speciation. Sunderland, Massachusetts USA: Sinauer Associates, Inc.; 2004.

67. Gwynne DT, Morris GK. Heterospecific recognition and behavioral isolation in acoustic Orthoptera (Insecta). Evol Theory. 1986;8:33-8.

68. Butlin RK, Hewitt GM. The response of female grasshoppers to male song. Anim Behav. 1986;34:1896-9.

69. Mayr E. Animal species and evolution. Cambridge: Belknap; 1963.

70. DeWoody JA, Bickham JW, Michler CH, Nichols KM, Rhodes GE, Woeste KE. Molecular approaches in natural resource conservation and management. New York: Cambridge University Press; 2010.

71. Johnson WE, Onorato DP, Roelke ME, Land ED, Cunningham M, Belden RC, et al. Genetic restoration of the Florida panther. Science. 2010;329:1641-5.
72. Hedrick PW. Gene flow and genetic restoration: the Florida panther as a case study. Conserv Biol. 1995;9:996-1007.

73. Hedrick P. Genetics of populations. Sudbury, MA: Jones \& Bartlett Publisher 2009

74. Wright S. Evolution in Mendelian populations. Genetics. 1931;16:97

75. Fitzpatrick BM, Shaffer HB. Hybrid vigor between native and introduced salamanders raises new challenges for conservation. Proc Natl Acad Sci. 2007:104:15793-8.

76. Sankararaman S, Mallick S, Dannemann M, Prääfer K, Kelso J, Pääbo S, et al. The genomic landscape of Neanderthal ancestry in present-day humans. Nature. 2014:507:354-7. 